\title{
The Relationship Between Trajectories of Child Maltreatment and Adolescent Suicidal Ideation
}

\author{
Se Won Kim, Deok-Seong Kim \\ Department of Social Welfare, Catholic Kwandong University, Gangneung, Korea \\ 아동의 종단적 학대 경험과 청소년기 자살생각 간 관계 \\ 김세원, 김덕성 \\ 가톨릭관동대학교 사회복지학과
}

Objective: The purpose of this study was to identify the longitudinal relationship between child maltreatment and adolescent suicidal ideation. Several studies suggest that child maltreatment is associated with adolescent suicidal ideation. However, these studies have not focused on the duration of child maltreatment.

Methods: Participants were 420 adolescents (52.6\% male; $47.4 \%$ female) involved in the Korea Welfare Panel Study. Data were collected via youth self-report in 2006, 2009, and 2012. A selfreport assessment of children and youths' experiences of physical, emotional, or neglect had been surveyed longitudinally. Questionnaires on adolescent suicidal ideation were answered in 2012. A growth mixture model and multiple regression were conducted using Mplus 5.21.

Results: The study results showed that $93.5 \%$ of the children had experienced no maltreatment; $6.5 \%$ had experienced increasing maltreatment longitudinally. The trajectory of increasing maltreatment was positively associated with adolescent suicidal ideation.

Conclusion: These results show that children suffering from chronic maltreatment are subject to a high risk of suicide and therefore require continuous supervision and management.

Keywords: child maltreatment, suicidal ideation, longitudinal study

\begin{abstract}
서론
여성가족부와 통계청이 발표한 '2015 청소년 통계'에 따르 면 2013년 기준 9-24세 청소년의 사망원인 1위는 '고의적 자 해(자살)'로 10 대 청소년의 경우 사망사례의 $27.1 \%$ 가 자살 로 사망하였다. Organisation for Economic Co-operation and Development (OECD) 31개국의 10-24세 아동 및 청소년의 자살률 통계를 보면 2000년 10만 명 당 7.7명에서 2010년 6.5

Corresponding Author: Se Won Kim, Department of Social Welfare, Department of Social Welfare, Catholic Kwandong University, 24, Beomilro 579beon-gil, Gangneung-si, Gangwon-do, Korea

E-mail: kimsw@cku.ac.kr
\end{abstract}

명으로 감소했다(Ministry of Gender Equality and Family \& Statistics Korea, 2015). 이 기간 한국의 같은 연령대 자살률은 6.4 명에서 9.4 명으로 $47 \%$ 급증하였고, 10 년 만에 순위가 18 위 에서 5 위로 상승했다. 또한 우리나라 청소년의 $30 \%$ 는 최근 1 년간 죽고 싶다는 생각을 해본 적이 있는 것으로 나타나(K. J. $\mathrm{Kim}, \mathrm{Kim}, \mathrm{Lee}, \& \mathrm{Kim}, 2014)$, 우리나라 청소년의 자살문제가 상당히 심각한 수준임을 알 수 있었다.

자살은 심리사회적, 신경생물학적, 정신병리학적 요인을

(C)The Korean Association of Child Studies

This is an Open Access article distributed under the terms of the Creative Commons Attribution Non-Commercial License (http:// creativecommons.org/licenses/by-nc/4.0) which permits unrestricted noncommercial use, distribution, and reproduction in any medium, provided the original work is properly cited. 
포함하여 복합적인 위험요인과 관련이 있는 현상이다. 지금까 지 여러 연구를 통해 자살생각과 자살시도 등과 같이 자살행 동의 위험을 증가시키는 요인들이 설명되었다. 초기에는 자살 생각 및 행동에 영향을 미치는 부정적인 생활스트레스에 관한 연구들이 주를 이루었지만, 최근에는 아동기의 아동학대경험 과 같이 외상적 스트레스와 자살 간의 관계를 설명하는 연구 들이 많아졌다(K. Y. Kim, 2008). 아동학대는 자살생각이나 자 살시도에 영향을 미치는 상당히 중요한 요인으로 나타났는데, 아동학대경험은 폭력에 대한 두려움과 수치심을 야기하여 자 기 자신에 대해 비난하게 만들고, 이러한 상황으로부터 벗어 날 수 없다고 생각되는 순간 자살생각과 행동으로 도피하게 된다(J. Y. Kim \& Lee, 2015).

아동학대가 자살생각에 미치는 영향을 생물학적으로 설 명한 연구를 살펴보면, 아동학대는 아동의 뇌구조와 기능 을 손상시킬 수 있는 신경생물학적 발달에도 영향을 미치고 (Cicchetti \& Valentino, 2006), 이로 인해 환경의 특성에 대처하 는 조절능력이 떨어지며, 자아통제 수준을 조절하는 능력을 방해하는 것으로 나타났다(Y. H. Kim, Kwon, \& Seo, 2008). 또 한 아동학대를 경험한 아동 - 청소년의 뇌는 유전자 발현의 차 이로 뇌 구조가 바뀌면서 성장한 이후 자살을 할 가능성을 높 이는 것으로 알려졌다. 캐나다 맥길대학의 Michael Meaney 교 수 팀은 아동기에 학대당한 뒤 자살을 한 집단과 학대경험이 없으나 자살한 집단, 갑자기 사고로 자살한 집단을 구분하여 각 집단별로 12 명의 뇌를 비교하였다. 연구결과 자살한 사람 과 그렇지 않은 사람의 뇌는 유전자 서열은 같지만, 학대경험 으로 인해 유전자 발현에 영향을 받아 스트레스 경로의 구조 가 바뀌고 이로 인해 자살률이 증가하는 것으로 나타났다(as cited in Jang \& Song, 2011). 다른 연구에서는 부모로부터 학대 를 받은 아동은 그렇지 않은 아동에 비해 자살위험이 3 배 더 높았고(Perkins \& Jones, 2004), 자살생각의 위험은 2배 이상 높 은 것으로 나타났다(Berenson, Wiemann, \& McCombs, 2001).

국내에서도 여러 연구를 통해 청소년의 자살생각과 학대 경험 간의 관계를 설명하였다. 아동기의 학대경험이 많을수 록 중학생 또는 고등학생 시기에 자살생각은 더욱 많아졌고 (Ryu \& Kim, 2012), 아동기에 경험한 정서적 학대와 방임 수 준이 높을수록 중학생의 자살생각 또한 많아지는 것으로 나타 났다(Jang \& Song, 2010). 아동기의 신체학대와 정서학대 경험 이 많을수록 대학생의 자살사고는 유의하게 높았으며(Lee, Ju, \& Hyun, 2015), 부모에게 학대를 많이 받은 청소년은 자살시 도는 하지 않았지만 자살생각은 더 많이 하는 것으로 나타났 다(Hong \& Chung, 2012). 아동기의 정서적 학대경험은 청소
년기 자살생각에 직접적인 영향을 줄뿐만 아니라 자기체계 손 상과 우울을 거쳐 간접적으로 영향을 미치기도 하였다(Chu \& Choi, 2015). 또한 아동기 학대경험은 대학생의 자살생각에 직 접적인 영향과 스트레스와 정신건강을 통해 간접적인 영향을 모두 미치는 것으로 나타났다(Choi, 2012). 가출청소년을 대상 으로 한 연구에서도 부모로부터 받은 학대경험이 많을수록 가 출청소년의 자살생각 수준은 더욱 높았다(J. Kim, Kim, Jang, $\& \mathrm{Han}, 2016)$. 청소년의 자살생각을 종단적으로 분석한 연구 에서는 아동학대와 방임의 경험이 많을수록 3 년간 자살생각 이 높은 궤적을 보이는 집단에 속할 가능성이 높았다(Park \& Nam, 2015).

외국의 연구에서는 일시적인 아동학대에 비해 학대가 반복 적으로 발생한 경우 자살행동의 위험이 더욱 높은 것으로 나 타났다(Brezo et al., 2008). 일시적인 학대보다 만성적으로 지속 되는 학대는 심리사회적 적응과 같은 아동발달에 더욱 부정적 인 영향을 미치는 것으로 나타났다(Bromfield \& Higgins, 2005; Jonson-Reid, Kohl, \& Drake, 2012). 만성적이고 지속적인 학대 는 비행행동을 더 많이 발생시키고(S. Kim \& Lee, 2010a), 폭 력수준을 높이며(Mersky \& Reynolds, 2007), 불법적인 약물사 용과 흡연, 알코올중독 가능성을 높이고 있다(Felitti \& Anda, 2009). 학대가 장기적으로 지속될 경우 피학대 아동은 부정적 인 자아이미지를 구성하여 우울, 불안, 공격성이 더욱 증가하 는 것으로 나타났으며(Jung, 2003), 이러한 위험요인들은 자살 생각이나 자살시도 등과 같은 자살위험성에 영향을 미치는 것 으로 알려져 있다.

우리나라에서 2014년 한 해 동안 아동보호전문기관에 신 고되어 아동학대로 판정된 사례 10,027 건의 학대발생 기간을 살펴본 결과, 일회성 학대는 $13.6 \%, 1$ 년에 한 번은 $2.4 \%, 1$ 년 에 두 번은 $7.0 \%$ 에 불과한 반면, 1 주일에 한 번은 $12.5 \%, 2-3$ 일에 한 번은 $13.7 \%$, 거의 매일 학대를 받은 아동은 $30.6 \%$ 로 학대아동의 상당수는 지속적으로 학대를 경험하는 것으 로 나타났다(Ministry of Health and Welfare \& National Child Protection Agency, 2015). 행정기관에 신고된 사례가 아니라 일반아동을 대상으로 학대경험을 조사한 연구에서는 아동기 부터 청소년기 동안 학대가 점점 더 증가한 경우가 응답자의 $6.6 \%$, 해당 기간 동안 학대가 감소한 경우도 $6.6 \%$, 학대가 발 생하지 않은 집단이 전체의 $86.4 \%$ 였다(S. Km \& Lee, 2010b). 외국의 연구에서는 반복적으로 만성적 학대를 경험하는 비 율을 9.3\% 43.0\% 수준으로 보고하고 있다(DePanfilis \& Zuravin, 1999; Fryer \& Miyoshi, 1994).

이와 같이 학대아동의 상당수는 일시적인 사건이 아니라 
반복적이고 지속적으로 학대에 노출되어 있는 것을 알 수 있 었다. 아동학대가 장기간 반복적으로 발생하는 이유는 가 정 내에서 가해자의 양육행동이나 양육조건이 쉽게 바뀌지 않기 때문에 동일한 유형의 학대가 반복되기 때문이다(Bae, Solomon, \& Gelles, 2007). 아동학대 사례 가운데 정도가 매우 심각한 극히 일부 사례만이 신고되며 대부분의 사례는 외부에 밝혀지지 않는다는 것을 고려하면 실제 만성적으로 학대를 경 험하고 있는 아동은 그 수가 더욱 많을 것으로 예측된다.

지금까지 살펴본 바와 같이 국내외의 여러 연구들은 아동 학대와 청소년의 자살생각 간의 인과관계를 설명하여 아동학 대의 부정적 영향을 실증적으로 보여주고 있다. 그러나 아직 까지 국내에서는 아동학대의 발생기간과 아동학대 피해 정도 를 모두 고려하여 자살생각 간의 관계를 설명한 연구가 부족 한 실정이다. 청소년의 자살생각이 종단적으로 어떻게 변화하 는지, 그리고 이러한 변화 유형과 아동기 학대경험 간의 관계 를 설명하거나(Park \& Nam, 2015), 아동기의 한 시점에서 경 험한 정서적 학대나 신체적 학대 경험이 이후 청소년기의 자 살생각에 미친 영향을 설명한 연구는 많이 있으나(Choi, 2012; Chu \& Choi, 2015; Lee et al., 2015; J. Y. Kim \& Lee, 2015; Ryu $\& \mathrm{Kim}, 2012)$, 아동의 종단적인 학대 피해경험과 청소년기 자 살생각 간의 관계를 설명한 연구는 거의 없다.

한편, 자살성(suicidality)의 구성체에 대한 연구에서는 다 양한 자살행동의 형태를 구분한다. 먼저, 자살생각(suicidal ideation)은 삶이 가치 없다고 느끼며 막연히 죽고 싶다는 생 각을 하게 되어 자신의 인생을 끝내기 위해 구체적인 계획을 세우는 자기 파괴적인 생각이다(Nock et al., 2009). 자살시도 (suicide attempt)는 죽으려는 의도를 가진 사람이 자신에게 해 를 끼치는 행위를 의도적으로 하는 것이다(Silverman, Berman, Sanddal, O'carroll, \& Joiner, 2007). 마지막으로 완료된 자살은 치명적인 자살시도의 결과이다. 연구에 따르면 사춘기 이전 의 청소년들은 자살을 실제행동으로 옮기기에 앞서, 자살에 대한 생각을 10 번 이상 하며, 자살생각을 한 첫 해에 자살계획 을 세우거나, 자살을 시도한다고 한다(Borges, Benjet, MedinaMora, Orozco, \& Nock, 2008). 자살생각의 정도가 심각한 사 람들 중 $42 \%$ 가 실제로 자살시도를 하였고, 자살생각의 정도 가 경미한 경우는 $34 \%$, 자살생각을 한 번도 하지 않은 사람은 자살시도를 하지 않은 것으로 나타났다(Carlson \& Cantwell, 1982). 자살생각을 했던 청소년은 자살생각을 하지 않았던 경 우에 비해 자살시도를 12 배 정도 더 많이 한 것으로 조사되었 다(Reinherz, Tanner, Berger, Beardslee, \& Fitzmaurice, 2006). 실 제 자살은 자살생각, 자살계획, 자살시도로 이어져 죽음에 이
르는 연속적 과정으로 연결되기 때문에 자살생각에 주목할 필 요가 있다.

따라서 본 연구에서는 종단적으로 아동학대에 노출된 기간 을 고려하여 아동학대가 청소년의 자살생각에 미치는 영향을 설명하고자 한다. 자살생각은 실제로 자살을 계획하고 이를 실행하는 행위와는 다르지만, 자살생각에 대한 이해는 자살문 제를 예방하고 개입하는데 유용한 정보를 제공해줄 수 있을 것이다.

한편, 아동학대와 같은 위험요인 외에 자살생각에 영향을 미치는 변인으로는 아동의 개인적 특성이나 가족관계 등이 있 다. 구체적으로 여자 청소년이 남자 청소년보다 자살생각을 더 많이 하며, 우울, 주의집중력, 공격성, 사회적 위축과 많은 신체화 증상 등이 자살생각에 영향을 미치는 것으로 나타났 다(Park \& Nam, 2015). 또한 부정적인 자기평가와 낮은 자아 존중감은 자살생각에 영향을 미치며, 높은 가족탄력성은 청소 년의 자살위험을 낮추는 것으로 나타났다(Ryu \& Kim, 2012). 부모의 학력수준(Jang \& Song, 2011), 가구소득이나(Park \& $\mathrm{Nam}, 2015)$, 가족환경의 질을 반영하는 가족의 사회경제적 상 태는 자살생각이나 자살시도에 유의미한 영향을 미치는 것으 로 나타났다(Brezo et al., 2008). 가족의 사회경제적 상태는 첫 아이 출산 당시 부모의 나이, 교육수준, 경제적 상태, 생활상태 등을 포함하여 측정하였다. 본 연구에서는 이와 같은 연구결 과를 고려하여 아동의 개인적 및 가족 특성을 포함하여 아동 학대와 자살생각 간의 인과관계를 설명하고자 한다. 본 연구 의 연구문제는 다음과 같다.

\section{연구문제 1.}

아동의 종단적 학대경험은 어떠한가?

\section{연구문제 2.}

아동의 종단적 학대경험 유형은 자살생각에 영향을 미치는가?

\section{연구방법}

\section{연구대상}

본 연구에서는 아동기의 종단적 학대경험이 청소년의 자살생 각에 미치는 영향을 파악하고자 하였다. 이를 위해 한국복지 패널(Korea Institute for Health and Social Affairs \& Social Welfare Research Center of Seoul National University, 2012) 가운데 아동 
용 부가조사 자료를 이용하였다. 한국복지패널은 연령, 소득계 층, 경제활동상태 등에 대한 다양한 인구집단별로 생활실태와 복지욕구 등을 역동적으로 파악하기 위해 2006년부터 전국에 거주하고 있는 총 7,000 가구를 대상으로 하여 매년 1회 조사 를 수행하고 있다. 아동용 부가조사는 가구원 가운데 2006년 1 차년도 조사 당시 초등학교 4, 5, 6학년에 재학 중이었던 아동 759 명을 대상으로 1 차, 4 차, 7 차년도까지 반복적으로 조사를 하였으며, 10차년도에는 2015년 기준 초등학교 4, 5, 6학년에 재학 중인 아동을 새롭게 선정하여 조사를 진행하였다.

아동용 부가조사에서 아동의 학대경험, 또래관계 및 학교 생활, 심리사회적 발달, 건강상태와 가족과 관련된 정보 등은 반복적으로 수집이 되었으며, 자살생각에 대한 자료는 7차년 도에 처음 수집되었다. 따라서 본 연구에서는 7차년도 조사 참 여한 아동 총 521 명을 연구대상으로 하여, 이들의 1 차, 4 차, 7 차년도의 아동학대경험을 파악하였다. 단, 7차년도 응답 아동 가운데 동일한 가구에서 여러 명의 아동이 조사에 응답한 경 우 첫 번째 아동만을 연구대상에 포함하였고, 자살생각에 응 답하지 않았거나 7차년도에 새롭게 조사에 참여한 신규아동 은 분석에서 제외하였다. 최종적으로 420 명의 아동이 연구대 상이 되었다. 아동의 학대경험은 1 차, 4 차, 7 차년도 시점에서 측정한 자료를 모두 사용하였고, 자살생각은 7차년도에 측정 한 자료를, 아동의 개인적 및 가족관련 변수들은 1 차년도의 자 료를 사용하였다.

\section{주요변수}

\section{종속변수}

청소년의 자살생각은 7차년도 시점에서 측정한 자료를 활용 하였으며, 자살생각을 측정하는 변수는 Raynolds (1988)의 자 살생각척도 (Suicidal Ideation Questionnaire [SIQ])를 활용한 6 개 문항으로 구성되어 있다. 구체적인 내용으로는 자살시도, 자살방법, 자살시기 등에 대한 생각을 물어보는 문항이 포함 되어 있다. 각 문항은 전혀 없다(0)부터 거의 매일(6)까지 7점 척도로 측정을 하였다. 본 연구에서는 자살생각에 대한 6 개 문 항에 대한 응답 점수를 모두 합하여 사용하였으며, 총점이 높 을수록 자살생각이 강한 것을 의미한다.

\section{독립변수}

아동의 학대경험은 아동부가조사가 실시된 $1,4,7$ 차년도에서
신체학대, 정서학대, 방임으로 구분하여 측정하였다. 1차년도 의 경우, 신체학대는 부모가 나를 밀쳐 벽에 머리를 부딪힌 일 이 있는지 등의 5 개 문항, 정서학대는 부모가 수치심과 모욕감 을 느낄 정도로 꾸짖은 일이 있는지 등의 3 개 문항, 방임은 내 가 늦게 와도 부모가 관심이 없다 등을 묻는 7개 문항으로 측 정하였다. 4차년도와 7차년도의 경우, 신체학대는 부모로부 터 심하게 맞은 적이 있는지 등에 대한 1 개 문항, 정서학대는 부모에게서 모욕적인 말을 들은 적이 있는지 등을 묻는 3 개 문 항, 방임은 부모의 학교생활, 불량오락실 출입 등에 대한 적절 한 감독 등을 묻는 3 개 문항으로 측정하였다.

아동의 학대경험 정도는 각 문항별로 전혀 없었다(0)부터 일주일에 1-2번 정도(4)까지 5점 척도로 측정하였다. 연도별 로 학대를 측정한 문항 수가 다른 것으로 고려하여 모든 문항 의 점수를 합한 후 총 문항 수로 나누어 연도별 학대 경험의 평 균 점수를 계산하여 사용하였다.

\section{통제변수}

아동의 학대경험 외에 아동의 자살생각에 영향을 미치는 아동 의 개인적 특성 및 가족 관련 변수는 통제변수로 투입하였으며, 이들 변수는 1 차년도 시점에 측정된 자료를 활용하였다. 먼저, 아동의 개인적 특성 가운데 아동의 생각 및 행동은 Achenbach (1991)가 개발한 아동, 청소년 행동평가 척도(Child Behavior Checklist [CBCL])를 Oh, Lee, Hong과 Ha (1997)가 번안한 $\mathrm{K}-\mathrm{CBCL}$ 척도를 사용하여 지난 6 개월 간의 경험을 조사하였다. 구체적으로는 첫째, 아동의 우울불안은 $\mathrm{K}-\mathrm{CBCL}$ 척도 가운데 13 개 문항을 이용하여 측정하였다. 둘째, 공격성은 19 개 문항으 로 측정하였으며, 각 문항별 점수는 0-2점 범위를 가지며, 변수 별로 모든 문항의 점수를 합하여 사용하였다. 점수가 높을수록 아동의 우울불안, 공격성 정도는 높은 것을 의미한다.

다음으로 아동의 자아존중감은 지난 1 년 간 자기 자신에 대 해 어떻게 느꼈는지를 내가 다른 사람만큼 가치 있는 사람이 라고 느낀다 등의 총 13 개 문항으로 측정하였다. 각 문항은 4 점 척도로 측정하였으며, 일부 문항은 역코딩을 한 후 문항별 점수를 모두 합하여 사용하였다. 총점이 높을수록 자아존중감 이 높은 것을 의미한다. 아동의 나이는 2006년 조사 시점 기준 나이를 연속변수로 측정하였으며, 아동의 성별은 남자 $=1$, 여 자 $=0$ 으로 구분하였다.

가족관련 변인으로는 첫째, 어머니의 학력 수준은 무학, 초 등학교, 중학교, 고등학교, 전문대학, 대학교, 대학원으로 구분 하여 측정하였다. 둘째, 가구의 수급여부는 기초생활보장수 
급 가구인 경우 1 , 비해당 가구는 0 으로 구분하였다. 셋째, 가 구형태는 한부모가구인 경우 1 , 부모가 모두 있는 경우 0 으로 측정하였다. 넷째, 가족갈등은 가족원 간 의견충돌이 잦은 경 우나 서로 비난하는 경우 등을 묻는 5 개 문항으로 측정하였다. 각 문항은 5점 척도로 측정하였으며 일부 문항은 역코딩하여 모든 문항의 점수를 합하여 사용하였다. 총점이 높을수록 가 족 간의 갈등 수준이 높은 것을 의미한다.

\section{자료분석}

본 연구에서는 아동의 종단적 학대경험과 자살생각 간의 관 계를 설명하기 위해 다음과 같이 자료를 분석하였다. 첫째, 종 단적 아동학대경험 유형을 파악하기 위하여 잠재적 변수 혼 합 모형(latent variable mixture model)의 일종인 성장혼합모형 (growth mixture model)을 실시하였다. 성장혼합모형은 종단 자료를 이용하여 전체 모집단 가운데 아동학대를 경험한 정 도에 따라 알려지지 않은 몇 개의 하위집단으로 구분되는가 를 파악하는데 유용한 분석방법이다. 아동의 종단적 학대경험 발달궤적은 $1,4,7$ 차년도에 측정된 아동의 학대경험평균값을 사용을 사용하여 선형함수로 추정하였다. 시간함수는 $\mathrm{T}=0$, 3,6 의 값을 갖는다. 이에 대한 연구모형은 Figure 1 과 같다. 둘 째, 성장혼합모형에 의해 구분된 종단적 아동학대경험 유형과 청소년기 자살생각 간의 인과관계를 설명하기 위하여 회귀분 석을 실시하였다. 분석은 Mplus 5.21 (Muthén \& Muthén, Los Angeles, CA)을 이용하였다.

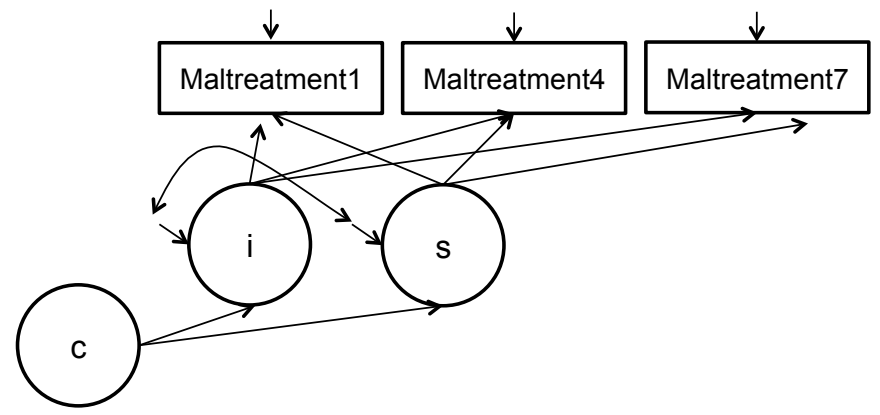

Figure 1. Growth mixture model of Child Maltreatment.

\section{연구결과}

\section{주요변수의 기술통계분석결과}

연구대상인 아동과 가족에 대한 인구학적 특성 및 주요변수
에 대한 분석결과는 Table 1 과 같다. 아동의 학대경험은 $1,4,7$ 차년도 자료를 활용하였으며, 이외 변인은 7차년도 자료를 분 석하였다. 먼저, 연구대상 아동 가운데 남자아동이 $52.6 \%$, 여 자아동이 $47.4 \%$ 였으며, 아동의 연령은 9 세가 $4.5 \%, 10$ 세가 $36.7 \%, 11$ 세가 $35.2 \%, 12$ 세가 $23.6 \%$ 였다.

조사에 참여한 아동 아버지의 교육수준은 고졸이하가 $52.4 \%$, 전문대졸 이상이 $31.0 \%$ 였다. 어머니의 교육수준은 고 졸이하가 $69.0 \%$, 전문대졸 이상이 $17.6 \%$ 였다. 아동이 속한 가구가 수급대상인 경우는 $12.1 \%$ 였고, 비수급가구가 $87.9 \%$ 였다. 아동의 부모가 모두 있는 가구는 $77.6 \%$, 한부모 가구는 $22.4 \%$ 로 나타났다.

다음으로 아동의 심리·정서적 특성과 관련된 변인을 살펴 본 결과, 1 차년도 아동학대 피해경험의 평균값은 $0.12(S D=$ $0.19), 4$ 차년도 평균값은 $0.17(S D=0.34), 7$ 차년도 평균값은 $0.15(S D=0.33)$ 이었다. 7차년도에 측정한 자살생각 평균값은 $2.11(S D=4.40)$ 이었고, 1 차년도에 측정한 우울불안 평균값 은 $4.52(S D=4.28)$, 공격성 평균값은 $4.50(S D=4.68)$, 자존감 평균값은 $25.60(S D=5.66)$, 아동 아버지의 평균 연령은 42.35 $(S D=4.59)$, 어머니의 평균 연령은 $38.93(S D=4.18)$ 이었다. 가족갈등의 평균값은 $3.75(S D=2.95)$ 로 나타났다.

\section{아동의 종단적 학대경험 유형}

1 차년도부터 7차년도까지 종단적으로 측정한 아동의 학대경 험에 대한 성장혼합모형을 분석하기 전에 연구대상자를 하나 의 집단으로 간주하여 다른 독립변수 투입없이 아동의 학대경 험 궤적의 초기치와 기울기를 살펴본 결과는 Table 2 와 같다. 아동의 학대경험은 시간이 가면서 약간 증가하는 것으로 나타 났고, 기울기의 분산이 통계적으로 유의하였다.

앞서 살펴본 바와 같이 아동의 학대경험 발달궤적의 기울기 분산이 유의하여, 아동의 종단적 학대경험은 하나의 궤적이 아 니라 여러 개의 각기 다른 발달궤적으로 구분될 수 있는 것으 로 볼 수 있다. 아동의 종단적 학대경험에 대한 하위집단을 구 분하기 위해 성장혼합모형 분석을 실시한 결과는 Table 3 과 같 다. 전체 모집단이 몇 개의 이질적인 하위집단으로 구분되는 지를 파악하기 위해 집단의 수를 하나씩 증가시키면서 AIC와 $\mathrm{BIC}, \mathrm{LMRT}$, 엔트로피 값 등을 살펴보았다. $\mathrm{AIC}$ 와 BIC는 작을 수록, LMRT값은 통계적으로 유의할 때(k개 모형이 k-1개 모 형보다 자료를 더 잘 설명함), 엔트로피 값은 1 에 가까울수록 모형이 자료를 보다 더 잘 설명하고 있는 것을 의미한다.

Table 2에서와 같이 발달궤적을 구분하는 집단의 수가 하나 
Table 1

Descriptive Statistics for All Study Variables

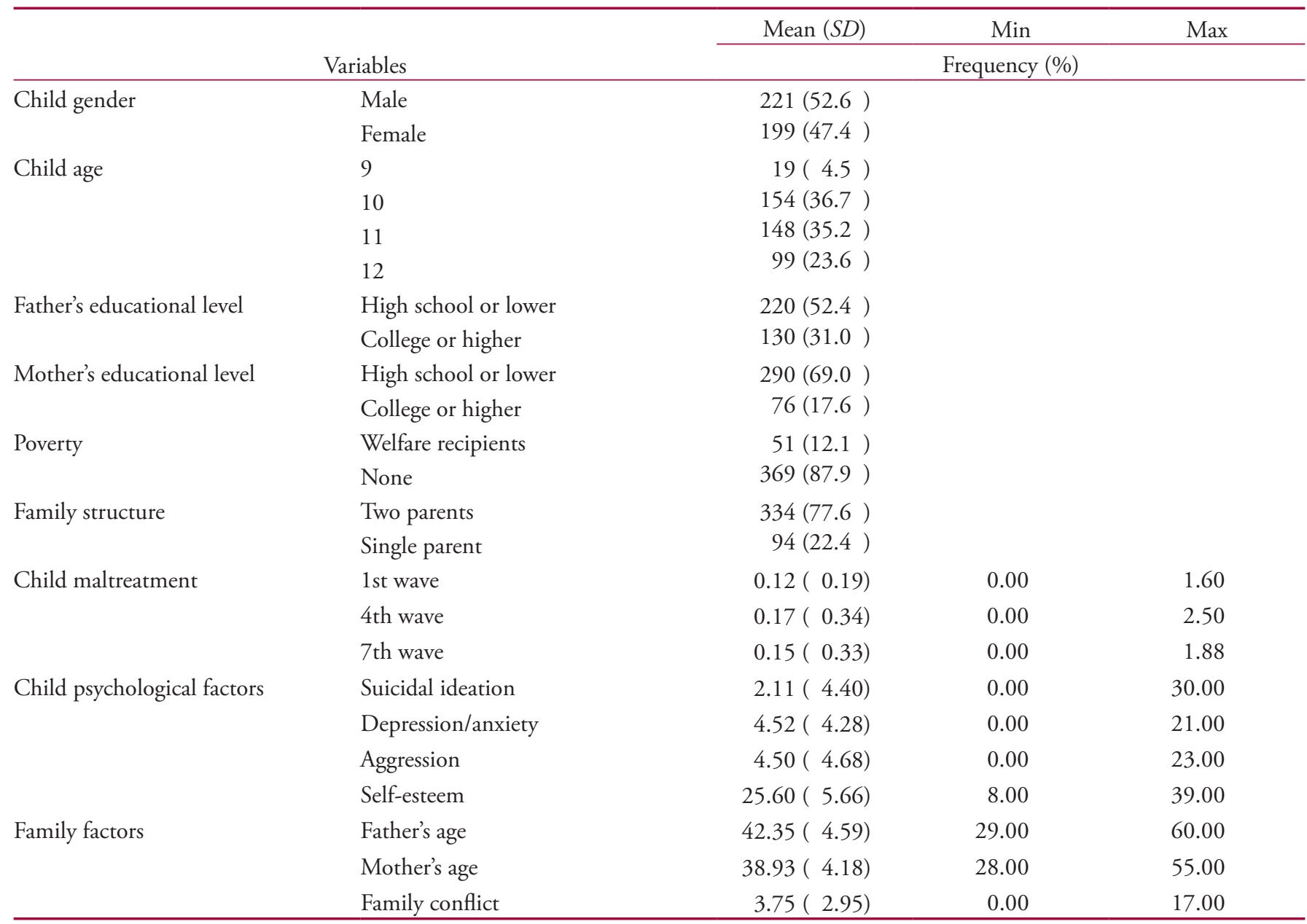

Note. $N=420$.

Table 2

Estimated Trajectory of Child Maltreatment

\begin{tabular}{llll}
\hline & & Intercept $(S E)$ & Slope $(S E)$ \\
\hline Child maltreatment & Means & $0.124(0.010)^{* *}$ & $0.006(0.003) \dagger$ \\
& Variances & $0.023(0.009)^{* *}$ & $0.002(0.001)^{*}$ \\
\hline
\end{tabular}

$\dagger p<.10 .^{*} p<.05 .{ }^{* *} p<.01$.

씩 늘어날 때마다 AIC와 BIC의 값은 감소하고 있으나, LMRT 값은 발달궤적을 2 개 집단으로 구분할 때만 유의하였다. 이때 엔트로피 값은 0.98 로 1 에 가깝게 나타났다. 즉 아동의 종단적 학대경험은 2 개의 발달궤적으로 구분할 때 자료를 최적으로 설명하고 있는 것으로 볼 수 있다.

최종적으로 구분된 아동의 종단적 학대 경험에 대한 발 달궤적 유형은 Table 4와 같다. 첫 번째 유형은 $1,4,7$ 차년도
세 시점에서의 아동학대 경험 정도가 상당히 낮고, 기울기 는 약간 감소하는 것으로 나타났다. 이 집단은 '아동학대 경 험 없음 집단으로 명명할 수 있을 것이다. 전체 아동 가운데 $93.5 \%(392$ 명 $)$ 가 이 유형에 속했다. 두 번째 유형은 1 차년도에 서의 아동학대 경험 정도는 아동학대 경험 없음 집단과 유사 했으나 시간이 흐르면서 아동학대 경험 정도가 점차 증가하는 것으로 나타났다. 이 집단은 '아동학대 증가' 집단으로 명명할 
Table 3

Model Fit Indices of Child Maltreatment Latent Class Growth Analysis

\begin{tabular}{lcrcr}
\hline & \multicolumn{3}{c}{ Fit index } \\
\cline { 2 - 5 } Number of latent profiles & AIC & BIC & LMRT & Entropy \\
\hline 1 & 263.46 & 295.78 & - & 0.98 \\
2 & -48.25 & -3.81 & $317.71^{*}$ & 0.97 \\
\hline
\end{tabular}

${ }^{*} p<.05$.

Table 4

Estimated Profiles of Child Maltreatment

\begin{tabular}{lccccc}
\hline & \multicolumn{2}{c}{ Class 1} & & \multicolumn{2}{c}{ Class 2 } \\
\cline { 2 - 3 } Profile type & Intercept $(S E)$ & Slope $(S E)$ & & Intercept $(S E)$ & Slope $(S E)$ \\
\hline Child maltreatment & $0.117(0.009)^{* *}$ & $-0.007(0.003)^{*}$ & & $0.213(0.072)^{* *}$ & $0.164^{* *}(0.017)$ \\
\hline$N(\%)$ & \multicolumn{2}{c}{$392(93.5 \%)$} & & $27(6.5 \%)$ \\
\hline
\end{tabular}

${ }^{*} p<.05 .{ }^{* *} p<.01$.

Table 5

Relationship Between Child Maltreatment and Suicidal Ideation

\begin{tabular}{|c|c|c|c|c|}
\hline & $B$ & $S E$ & $\beta$ & $t$ \\
\hline Intercept & -2.66 & 3.55 & & -0.75 \\
\hline $\begin{array}{l}\text { Child maltreatment } \\
\quad(\text { increasing maltreatment }=1)\end{array}$ & $2.37^{*}$ & 1.08 & 0.11 & 2.19 \\
\hline Aggression & $0.13^{*}$ & 0.06 & 0.12 & 1.98 \\
\hline Self-esteem & 0.01 & 0.05 & 0.01 & 0.24 \\
\hline Depression/anxiety & $0.16^{*}$ & 0.07 & 0.15 & 2.25 \\
\hline Child age & 0.41 & 0.27 & 0.08 & 1.52 \\
\hline Child gender $($ boy $=1)$ & $-1.22^{*}$ & 0.48 & -0.13 & -2.55 \\
\hline Mother's education level & -0.06 & 0.26 & -0.01 & -0.25 \\
\hline Single parent & -0.79 & 0.82 & -0.05 & -0.95 \\
\hline Welfare recipients & $2.07^{*}$ & 1.01 & 0.12 & 2.05 \\
\hline Family conflict & -0.10 & 0.08 & -0.07 & -1.27 \\
\hline$F$ & & $4.46^{* *}$ & & \\
\hline$R^{2}$ & & .11 & & \\
\hline Adjusted $R^{2}$ & & .09 & & \\
\hline
\end{tabular}

Note. $N=420$.

${ }^{*} p<.05 .{ }^{* *} p<.01$.

수 있으며, 전체 아동 가운데 6.5\%(27명)가 이 유형에 속하는 것으로 나타났다.

Table 4에서 구분된 아동의 종단적 학대 경험 유형의 발달궤 적의 그래프는 다음과 같다. 아동학대 증가 집단의 크기는 작지 만 시간이 흐를수록 아동학대의 경험이 오히려 증가한다는 측 면에서 아동학대 문제가 심각한 집단으로 볼 수 있을 것이다.

\section{아동의 종단적 학대경험이 자살생각에 미치는 영향}

아동의 종단적 학대경험과 자살생각 간의 인과관계를 설명하 기 위하여, 성장혼합모형 분석결과에서 나타난 아동의 종단적 학대경험 유형을 독립변수로, 자살생각 여부를 종속변수로 하 


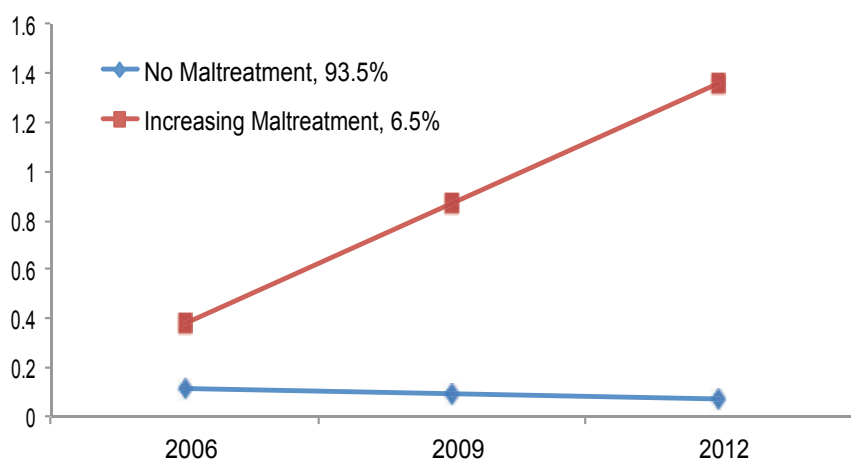

Figure 2. Trajectories of child maltreatment.

여 다중회귀분석을 실시하였다. 그 외 선행연구에서 청소년의 자살생각에 영향을 미치는 것으로 나타난 변인을 함께 투입하 여 분석을 하였으며, 결과는 Table 5 와 같다.

먼저, 아동의 종단적 학대경험은 아동학대 증가 집단 $=1$, 아동학대 경험 없음 집단 $=0$ 으로 하여 분석하였다. 분석결과 아동학대 증가 집단이 아동학대 경험 없음 집단에 비해 청소 년기에 자살생각을 좀 더 많이 하는 것으로 나타났으며, 이는 신뢰수준 $95 \%$ 에서 통계적으로 유의하였다. 즉 종단적으로 아 동학대에 노출된 정도가 심한 아동이 청소년기 자살생각이 증 가하였다.

한편, 아동의 학대경험 외에 아동기의 공격성과 우울불안 의 정도가 높을수록 청소년기에 자살생각을 더 많이 하는 것 으로 나타났으며, 남자아동은 여자아동보다 청소년기 자살생 각을 덜 하며 수급가구 아동인 경우 비수급가구의 아동보다 청소년기 자살생각을 더 많이 하는 것으로 나타났다. 이들 변 인은 모두 신뢰수준 $95 \%$ 에서 통계적으로 유의하였다. 아동의 나이와 자존감, 어머니의 학력수준, 가구유형이나 가족갈등 등과 같은 변인은 청소년기 자살생각에 통계적으로 유의한 영 향을 미치지 않는 것으로 나타났다.

\section{논의 및 결론}

본 연구에서는 아동의 종단적 학대경험이 청소년기 자살생각 에 미치는 영향을 파악하고자 하였다. 이를 위해 한국복지패 널 1차, 4 차 및 7 차년도 응답아동 420 명의 아동용 부가조사 및 가구자료를 활용하여 성장혼합모형과 다중회귀분석을 실시 하였다. 먼저, 성장혼합모형을 이용하여 1차, 4,차 및 7차 시점 에서 측정한 아동의 학대 피해경험 정도가 어떤 발달궤적으로 변화하는가를 선형함수로 추정하였다. 이때 전체 아동의 학대
경험은 알려지지 않은 몇 개의 이질적인 하위집단으로 구분된 다고 가정하고, 자료를 가장 잘 설명할 수 있는 하위집단의 수 를 찾기 위해 $\mathrm{AIC}, \mathrm{BIC}, \mathrm{LMRT}$ 값과 엔트로피 값 등을 사용하 였다.

분석 결과 아동의 종단적 학대경험은 2 개의 발달궤적으로 구분할 수 있었다. 첫 번째 발달궤적은 1 차년도에 측정한 아동 의 학대 피해경험 초기치가 낮고 이후 시간이 흐르면서 학대 경험 기울기가 약간 감소하는 형태를 보였다. 이는 아동학대 경험 없음 집단으로 볼 수 있으며 전체 아동의 약 $93.5 \%$ 가 이 유형에 속하였다. 즉 대부분의 아동은 1 차년도에서 7 차년도 의 기간 동안 아동학대를 거의 경험하지 않는 것으로 볼 수 있 다. 두 번째 발달궤적은 1차년도에는 아동학대 경험 없음 집단 과 초기치의 수준이 거의 유사하였으나 기울기가 (+) 값을 갖 고, 이는 통계적으로 유의한 것으로 나타났다. 즉 1차년도 이 후 시간이 지나면서 아동의 학대경험 정도는 점차 증가하는 것으로 볼 수 있다. 이는 아동학대 증가 집단으로 볼 수 있으 며, 전체 아동 중 약 $6.5 \%$ 가 이 집단에 속하였다. 전체 아동 가 운데 이 유형에 속하는 아동의 비율이 크지는 않지만, 이들은 1 차년도부터 7차년도까지 긴 시간동안 학대에 노출된 정도가 심한 고위험 집단으로 볼 수 있을 것이다. 본 연구에서 사용한 자료는 신고된 아동학대 정보가 아니라 일반아동의 자기기입 식 방법으로 수집된 것을 고려했을 때, 적지 않은 수의 아동이 지속적으로 아동학대에 노출되고 있으며 우리나라 아동학대 문제의 심각성을 알 수 있다. 아동학대 문제를 해결하고 예방 하기 위해서는 무엇보다 학대아동을 발견하여 아동복지서비 스 시스템 내에서 필요한 도움을 받을 수 있게 해야 한다. 이를 위해 아동을 가까이에서 관찰할 수 있는 교사와 의사 등과 같 은 신고의무자의 신고 활성화와 아동학대 인식개선을 위한 개 입 등이 지속적으로 시행되어야 할 것이다.

이와 같은 아동의 종단적 학대경험 유형과 청소년기 자살 생각 간의 관계를 설명하기 위해 다중회귀분석을 실시하였다. 청소년기의 자살생각은 자살생각 여부, 자살행동에 대한 생각 여부 등과 같이 자살에 대해 생각을 얼마나 자주 했는가로 측 정하였다. 각 문항을 모두 합한 점수가 높을수록 자살생각이 높은 것을 의미한다. 아동의 종단적 학대경험 유형(아동학대 증가 집단 $=1)$ 을 독립변수로, 청소년기의 자살생각을 종속변 수로 하여 분석을 실시한 결과, 아동학대 증가 집단은 아동학 대 경험이 없는 집단보다 청소년기에 자살생각을 더 많이 하 는 것으로 나타났으며, 이는 통계적으로 유의하였다. 이외에 아동기의 공격성과 우울불안 수준 또한 청소년기의 자살생각 에 정적인 영향을 미쳤으며, 남아가 여아보다 청소년기에 자 
살생각을 덜 하고, 수급가정의 자녀인 경우 청소년기에 자살 생각을 더 많이 하는 것으로 나타났다.

즉 본 연구는 종단적 아동학대 경험과 자살생각 간의 인과 관계를 실증적으로 설명하였으며, 아동학대가 자살생각에 대 한 강력한 위험요인임을 보여주었다. 이는 장기간 반복적으 로 발생하는 만성적인 아동학대는 아동발달에 더욱 부정적인 영향을 미치며(Bromfield \& Higgins, 2005; Jonson-Reid et al., 2012), 불법적인 약물사용과 흡연, 알코올중독 가능성(Felitti $\&$ Anda, 2009), 부정적인 자아이미지, 우울, 불안, 공격성이 더 욱 증가하고(Jung, 2003), 이러한 위험요인들은 자살생각이나 자살시도 등과 같은 자살위험성에 영향을 미치며, 만성적이고 반복적으로 학대를 경험한 경우 자살행동의 위험이 더욱 높았 다(Brezo et al., 2008)는 선행연구 결과와 일관되는 것으로 볼 수 있을 것이다.

이러한 결과는 장기간 반복적으로 학대에 노출된 아동은 자살위험이 높은 대상으로 지속적인 관리 감독할 필요가 있음 을 보여준다. 예를 들어, 아동보호전문기관에 신고되어 학대 로 판정된 사례의 아동에 대한 개입 시 아동학대에 노출된 기 간과 정도를 고려하여 아동의 자살생각이나 자살시도 등의 위 험성을 파악하고 이에 대한 상담과 지속적인 관리 감독이 필 요할 것이다. 또한 아동이 원가정 복귀를 하거나 아동보호시 설로 입소할 경우 이들을 보호하는 부모, 시설운영자나 생활 지도교사 등에게 아동학대와 자살생각 간의 관계, 자살의 위 험 징후 등에 대해 교육하고 필요한 경우 적절한 개입과 전문 적인 도움을 받을 수 있도록 안내할 수 있을 것이다. 그러나 무 엇보다 가능한 학대아동을 조기에 발견하여 아동학대 재발생 을 예방할 수 있는 서비스를 제공할 필요가 있다. 연구결과에 서 나타난 바와 같이 아동학대에 노출된 아동은 일시적이 아 니라 지속적이고 반복적으로 학대에 노출되어 있기 때문에 만 성적 학대를 중단하기 위한 효과적인 개입 시점과 개입의 질 을 이해하는 것이 선행되어야 할 것이다.

한편, 아동학대와 자살문제 간의 관계에 대해서는 선행연 구마다 다소 차이가 있었다. 일부 연구에서는 부모로부터 학 대를 받은 아동의 자살위험이 더 높게 나타났으나(Berenson et al., 2001; Perkins \& Jones, 2004). 또 다른 연구에서는 아동기의 학대경험이 청소년이나 성인의 자살행동과 관련이 없는 것으 로 나타나기도 했다(Brent et al., 1993). 이러한 연구결과의 차 이는 아동학대 외에 다른 아동기 요인들이 나중의 자살행동에 잠재적으로 교란효과(confounding effects)를 미치는데서 비롯 된 것일 수 있다. 그러나 본 연구에서는 자살생각에 영향을 미 치는 다른 변인들을 통제한 상태에서 아동학대와 자살행동 간
의 관계를 설명하였으며, 특히 아동학대의 기간과 정도를 동 시에 고려하여 아동학대의 위험성을 실증적으로 규명하였다 는 측면에서 의의가 있다. 장기적이고 반복적인 아동학대는 아동발달에 누적적으로 영향을 미칠 수 있으며, 이로 인해 아 동학대가 지속될수록 아동발달결과는 더욱 부정적으로 나타 날 수 있을 것이다.

이러한 연구결과를 통해 다음과 같은 실천적 함의를 도출 할 수 있을 것이다. 첫째, 우리나라 전체 아동 중 일부는 장기 적이고 반복적인 학대에 노출되어 있다. 아동을 가까이에서 관찰할 수 있는 교사나 의사 등에 대한 아동학대 신고와 인식 에 대한 교육을 더욱 강화하여 피학대 아동을 조기에 발견하 고 개입하여 자살생각에 미치는 위험요인의 부정적인 영향을 감소시킬 필요가 있다. 둘째, 자살위험 청소년을 평가하는 임 상가나 실천가는 사정 시 반드시 아동학대경험을 파악할 필요 가 있다. 셋째, 아동학대를 포함한 부모의 양육태도, 수급여부 와 같은 가족관련 요인 등이 자살생각에 영향을 미치는 것을 고려하여, 자살위험 청소년에 대한 개입 시 부모를 포함한 가 정환경에 대해 개입할 필요가 있을 것이다. 즉 환경의 위험요 인을 제거 또는 감소시키는 것은 자살위험을 감소시키는데 효 과가 있을 것이다.

이와 같은 함의에도 불구하고 본 연구는 다음과 같은 제한 점을 갖는다. 첫째, 본 연구에서 사용한 한국복지패널 데이터 에는 아동의 성학대 경험에 대한 정보는 포함되어 있지 않다. 따라서 본 연구에서는 아동의 성학대 피해경험이 자살생각에 미치는 영향을 설명하지 못하였다. 지금까지 여러 외국의 선 행연구에서 아동 성학대가 아동발달이나 심리·정서적 문제에 미치는 영향이 다른 학대유형과는 다소 차이가 있다는 것이 보고되고 있음에도 불구하고, 우리나라에서는 자료의 제한점 으로 인해 이러한 인과관계를 실증적으로 규명하는데는 어려 움이 있다. 성학대 문제를 효과적으로 해결하기 위해서는 문 제 발생의 원인 및 결과에 대한 이해가 필요하며, 이를 위해서 는 체계적인 관련 자료의 수집이 선행되어야 할 것이다. 둘째, 본 연구에서는 아동의 학대경험을 종단적으로 유형화하였으 나 신체적 학대, 정서적 학대나 방임의 하위유형별 또는 각 하 위유형의 조합별로 자살생각이 미치는 영향이 차이가 있는지 여부는 설명하지 못하였다. 추후 연구에서는 아동학대의 유형 과 정도를 모두 고려하여 자살생각 간의 관계를 설명할 필요 가 있을 것이다. 


\section{Acknowledgements}

This work was supported by research fund Catholic Kwandong University (CKURF-201603920001)

\section{Conflict of Interest}

No potential conflict of interest relevant to this article was reported.

\section{References}

\section{In Enlgish}

Bae, H.-O., Solomon, P. L., \& Gelles, R. J. (2007). Abuse type and substantiation status varying by recurrence. Children and Youth Services Review, 29(7), 856-869. doi:10.1016/ j.childyouth.2007.01.002

Berenson, A. B., Wiemann, C. M., \& McCombs, S. (2001). Exposure to violence and associated health-risk behaviors among adolescent girls. Archives Pediatrics \& Adolescent Medicine, 155(11), 1238-1242. doi:10.1001/archpedi.155.11.1238

Borges, G., Benjet, C., Medina-Mora, M. E., Orozco, R., \& Nock, M. (2008). Suicide ideation plan, and attempt in the Mexican adolescent mental health survey. Journal of the American Academy of Child \& Adolescent Psychiatry, 47(1), 41-52. doi:10.1097/chi.0b013e31815896ad

Brent, D. A., Perper, J. A., Moritz, G., Allman, C., Friend, A., Roth, C., . . . Baugher, M. (1993). Psychiatric risk factors for suicide: A case control study. Journal of the American Academy of Child \& Adolescent Psychiatry, 32, 521-529. doi:10.1097/00004583-199305000-00006

Brezo, J., Paris, F., Vitaro, F., M. Hebert, M., Tremblay, R. E., \& Turecki, G. (2008). Predicting suicide attempts in young adults with histories of childhood abuse. British Journal of Psychiatry, 193(2), 134-139. doi:10.1192/bjp.bp.107.037994

Bromfield, L. M., \& Higgins, D. J. (2005). Chronic and isolated maltreatment in a child protection sample. Family Matters, $70,38-45$.

Carlson, G. A., \& Cantwell, D. P. (1982). Suicidal behavior and depression in children and adolescents. Journal of the American Academy of Child Psychiatry, 21(4), 361-368. Retrieved from http://www.jaacap.com

Cicchetti, D., \& Valentino, K. (2006). An ecological-transactional perspective on child maltreatment: Failure of the average expectable environment and its influence on child development. In D. Cicchetti \& D. J. Cohen (Eds.), Development and psychopathology (Vol. 3, 2nd ed.). New York: Cambridge University Press.

DePanfilis, D., \& Zuravin, S. J. (1999). Epidemiology of child maltreatment recurrences. Social Service Review, 73(2), 218 239. doi: $10.1086 / 514415$

Felitti, V. J., \& Anda, R. (2009). The relationship of adverse childhood experiences to adult medical disease, psychiatric disorders, and sexual behavior: Implications for healthcare. In R. A. Lanius, E. Vermetten, \& C. Pain (Eds.), The impact of early life trauma on health and disease: The hidden epidemic. Cambridge, UK: Cambridge University Press.

Fryer, G. E., \& Miyoshi, T. J. (1994). A survival analysis of the revictimization of children: The case of Colorado. Child Abuse \& Neglect, 18(12), 1063-1071. doi:10.1016/01452134(94)90132-5

Jonson-Reid, M., Kohl, P. L., \& Drake, B. (2012). Child and adult outcomes of chronic child maltreatment. Pediatrics, 129(5), 839-845. doi:10.1542/peds.2011-2529

Mersky, J. P., \& Reynolds, A. J. (2007). Child maltreatment and violent delinquency: Disentangling main effects and subgroup effects. Child Maltreatment, 12(3), 246-258. doi:10.1177/1077559507301842

Mplus (Version 5.21) [Computer software]. Los Angeles, CA: Muthén \& Muthén.

Nock, M. K., Hwang, I., Sampson, N., Kessler, R. C., Angermeyer, M., Beautrais, A., . . . Williams, D. R. (2009) Crossnational Analysis of the associations among mental disorders and suicidal behavior: Findings from the WHO World Mental Health Surveys. PLoS Medicine, 6(8), e1000123. doi:10.1371/journal.pmed.1000123

Perkins, D. F., \& Jones, K. R. (2004). Risk behaviors and resiliency within physically abused adolescents. Child Abuse \& Neglect, 28(5), 547-563. doi:10.1016/j.chiabu.2003.12.001

Reinherz, H. Z., Tanner, J. I., Berger, S. R., Beardslee, W. R., \& Fitzmaurice, G. M. (2006). Adolescent suicidal ideation as predictive of psychopathology, suicidal behavior, and compromised functioning at age 30. The American Journal of Psychiatry, 163(7), 1226-1232. doi:10.1176/appi. ajp.163.7.1226

Reynolds, W. M. (1988). Suicidal Ideation Questionnaire: Professional manual. Odesa, FL: Psychological Assessment Resources.

Silverman, M. M., Berman, A. L., Sanddal, N. D., O'carroll, P. W., \& Joiner, T. E. (2007). Rebuilding the tower of Babel: A revised nomenclature for the study of suicide and suicidal behaviors Part 2: Suicide-related ideations, communications, and behaviors. Suicide Life-Threatening Behavior, 37(3), 264-277. doi:10.1521/suli.2007.37.3.264 


\section{In Korean}

Choi, Y. (2012). Effects of suicidal ideation in college students who report a history of childhood abuse. Journal of Adolescent Welfare, $14(2), 307-333$.

Chu, K.-J., \& Choi, J.-O. (2015). The relationships between childhood emotional maltreatment and adolescent suicidal ideation: The mediating effects of a traumatized self-system and depression. The Korean Journal of the Human Development, 22(4), 83-103. doi:10.15284/ kjhd.2015.22.4.83

Hong, N. \& Chung, Y. (2012). Path analysis on adolescent's suicidal ideation: A comparison of adolescent suicide attempters and non-attempters. Journal of the Korean Society and Child Welfare, 40, 255-283.

Jang, Y.-H., \& Song, J.-H. (2011). Influence of the experience of the childhood abuse on the self-esteem and suicidal thought in the adolescence period. Policy and Science, 20(2), 80104. Retrieved from http://www.riss.kr/link? id=A82701000

Jung, Y.-S. (2003). The effects on child's mental health of spouse violence and child abuse (Master's thesis). Retrieved from http://www.riss.kr/link?id=T9657866

Kim, J. Y., \& Lee, K. (2015). Effect of adolescents' abuse experience on suicidal ideation: Focused on moderated mediation effect of self-esteem on depression and anxiety. Journal of Korean Academy of Nursing, 45(5), 752-760. doi:10.4040/jkan.2015.45.5.752

Kim, J., Kim, J., Jang, Y., \& Han, K. (2016). The effects of the co-occurrence of child abuse and school victimization on the suicidal ideation among runaway adolescents: With a particular focus on the mediating effects of aggression. Studies on Korean Youth, 27(2), 159-186. doi:10.14816/ sky.2016.27.2.159

Kim, K. J., Kim, H. J., Lee, M. H., \& Kim, Y. N. (2014). Study on condition of Korean children and youth rights VI: Statistics of 2014 children and youth rights (Report No. 14-R14). Retrieved from https://www.nypi.re.kr

Kim, K. Y. (2008). The relationship between childhood abuse and neglect, suicidal ideation and alexithymia among adolescents (Master's thesis). Retrieved from http://www.riss.kr/ link?id=T11577896

Kim, S., \& Lee, B. J. (2010a). A study on the relationship between latent classes of child maltreatment and delinquency in the transition from childhood to adolescence. Journal of Korean Council for Children \& Rights, 14(3), 327-353. Retrieved from http://www.newnonmun.com/article $=22660$

Kim, S., \& Lee, B. J. (2010b). Latent profiles analysis of child maltreatment and adjustment. The Korean Journal of the Human Development, 17(1), 173-189. Retrieved from http://www.newnonmun.com/article=21235

Kim, Y. H., Kwon, S. M., \& Seo, S. G. (2008). The longitudinal relationship between peer relationship problems and depression/anxiety using autoregressive crosslagged modeling. Studies on Korean Youth, 19(4), 57-79. Retrieved from http://www.dbpia.co.kr/Journal/ArticleDetail/ NODE01090231

Korea Institute for Health and Social Affairs, Social Welfare Research Center of Seoul Nation University (2012). Korea welfare panel study. Retrieved from https://www.koweps. re.kr

Lee, K. B., Ju, H. W., \& Hyun, M. H. (2015). The moderating effects of forgiveness on the relationship between childhood abuse and suicidal ideation. The Korea Journal of Youth Counseling, 23(2), 21-36. Retrieved from https://www.kyci. or.kr/fileup/lib_pdf/2015-119-2.pdf

Ministry of Gender Equality and Family, Statistics Korea. (2015). 2015 national statistics on adolescents. Retrieved from http://www.kostat.go.kr

Ministry of Health and Welfare, National Child Protection Agency. (2015). National statistics on child abuse. Retrieved from https://korea1391.go.kr

Oh, K. J. Lee, H. L., Hong, K, \& Ha, E. Y. (1997). Korean Child Behavior Checklist (K-CBCL). Seoul: Chungang Jeokseong Research Center.

Park, J. Y., \& Nam I. (2015). Group developmental trajectories of adolescent suicidal ideation and associated predictors. Mental Health and Social Work, 43(3), 82-106.

Ryu, B. S., \& Kim, Y. S. (2012). The Influence of Adolescence Abuse Experience to Suicide: Focusing on Policy Implications. Journal of the Korea Society of Computer and Information, 17(10), 193-202. doi:10.9708/jksci/2012.17.10.193

\section{ORCID}

Se Won Kim

Deok-Seong Kim http://orcid.org/0000-0001-9116-8252

http://orcid.org/0000-0002-8523-9728
Received December 31, 2016

Revision received March 17, 2017

Accepted March 28, 2017 